\title{
Dealing with Peri-implant Soft Tissue Complication in the Esthetic Area: A Case Report
}

\author{
Maria Costanza Soldini ${ }^{1}$, Isabel Arroyo ${ }^{2}$, Ramon Pons ${ }^{3}$
}

\begin{abstract}
High esthetical result outcomes can be achieved with immediate implant-supported crowns in the esthetic zone despite the impossibility to perform an immediate provisionalization. This case report describes the management of a soft tissue complication of two dental implants in the esthetic area. Two immediate dental implants were placed in positions 1.1 and 2.1, while immediate loading was not possible due to low primary stability instead. At the time of loading, the gingival margin of implant 2.1 was apically positioned, volume deficiency was present and partial loss of the interdental papilla between the two central incisors was observed. The soft tissue discrepancy was managed by correctly modifying the critical and subcritical contour of the provisional restoration. The described customization technique of the provisional prosthesis offers satisfactory results in terms of esthetics and soft-tissue stability over time. This case report describes a technique for successfully managing slight soft tissue deficiency around implants, avoiding additional surgical interventions.

Keywords: Dental implants, Esthetic dentistry, Immediate provisionalization, Implant prosthesis, Peri-implant tissue, Platform switching, Temporization.

International Journal of Prosthodontics and Restorative Dentistry (2021): 10.5005/jp-journals-10019-1330
\end{abstract}

\section{BACKGROUND}

The achievement of an optimal esthetic outcome, with implantsupported crowns in the esthetic zone, is still one of the greatest challenges in implant dentistry. It seems to be particularly evident for immediate or type I implant placement protocols, characterized by implant placement at either the time of tooth extraction or shortly after it ( $<10$ days). ${ }^{1}$ Several studies evaluating the clinical outcomes of different time points of implant placement following a tooth extraction have reported lower esthetic outcomes for the immediate protocol ${ }^{2,3}$ due to the mucosal recession that was one of the most frequent complications observed. ${ }^{4}$ After tooth extraction, some dimensional alterations of the alveolar ridge can be expected. In this sense, the buccal bone tends to resorb followed by the collapse of soft tissue, thereby giving an unpleasant appearance of the restored site. ${ }^{5,6}$ The esthetic outcome depends on several surgical and prosthetic factors that should be controlled and properly managed. The extraction of the tooth, ${ }^{7}$ the buccal bone and mucosal thickness, ${ }^{6,8}$ the 3D implant position, ${ }^{9}$ the contour of the abutment, ${ }^{10}$ and the provisionalization ${ }^{11}$ would be some of them. The outcome of the implant-supported restoration in the esthetic zone is demanding since its success depends on its visual integration with the adjacent teeth. Hence, after the implant insertion, the implant-supported prosthesis must replicate the natural tooth shape, shade, and emergence profile.

\section{Case Description}

A 42-year-old female patient with no significant medical history consulted SBM private practice (Vicenza, Italy), for a complete evaluation and dental treatment. The dental team performed a clinical examination and a radiographic study of the patient (Fig. 1). The patient reported trauma history on teeth 1.1 and 2.1, in which a type II mobility was clinically appreciable. In addition, the radiographic analysis showed the presence of external root resorption and a periapical lesion associated with tooth 11. Based on all the information gathered, the dental team decided to extract
${ }^{1}$ Department of Periodontics, Institute for Dental and Implant Studies, Vicenza, Italy

${ }^{2}$ Private Practice, Castellon, Spain

${ }^{3}$ Maxilonet Barcelona Hospital Universitari Dexeus, Barcelona, Spain

Corresponding Author: Maria Costanza Soldini, Department of Periodontic, Institute for Dental and Implant Studies, Vicenza, Italy, Phone: +393491302895, e-mail: costanzasoldini@hotmail.it

How to cite this article: Soldini MC, Arroyo I, Pons R. Dealing with Periimplant Soft Tissue Complication in the Esthetic Area: A Case Report. Int J Prosthodont Restor Dent 2021;11(3):151-155.

Source of support: Nil

Conflict of interest: The author MARIA COSTANZA SOLDINI report the involvement in consultancies with $\mathrm{CLC}$ Conic ${ }^{\oplus}, \mathrm{CLC}$ SCIENTIFIC ${ }^{\circledR}$ with non-financial interest in the subject matter or materials discussed in this manuscript.

teeth 1.1 and 2.1 and, after a clinical and pre-surgical evaluation of the $\mathrm{CBCT}$, immediate implant placement was planned.

Two immediate dental implants of $3.5 \mathrm{~mm}$ diameter and 12 $\mathrm{mm}$ length were placed in positions 1.1 and 2.1 (CLC Conic ${ }^{\oplus}, \mathrm{CLC}$ SCIENTIFIC ${ }^{\circledR}$, Vicenza, Italy) with a surgical stent (Fig. 2). The insertion torque of the two implants at the time of placement was $20 \mathrm{~N} /$ $\mathrm{cm}$. They were left healing, and the closure caps (CLC SCIENTIFIC ${ }^{\circledast}$, Vicenza, Italy) were screwed with manual torque. Finally, two free connective tissue grafts with a diameter corresponding to the socket orifice (measured with a periodontal probe) were harvested from the palatal area at the level of the teeth 1.4-1.6. The grafts of 2-3 mm thick were cut, gently removed with a sharp tissue elevator, placed on the top of the socket, and sutured to the de-epithelialized soft tissue margins with a polyamide $5-0$ suture (Supramid ${ }^{\circledR}$, B. Braun ${ }^{\circledR}$ Melsungen AG, Germany) (Fig. 3). Due to the low insertion torque, it was not possible to perform an immediate loading. The esthetic was obtained with a fixed metal-reinforced laboratory-fabricated provisional restoration cemented with adhesive cement (Variolink ${ }^{\circledR}$ 

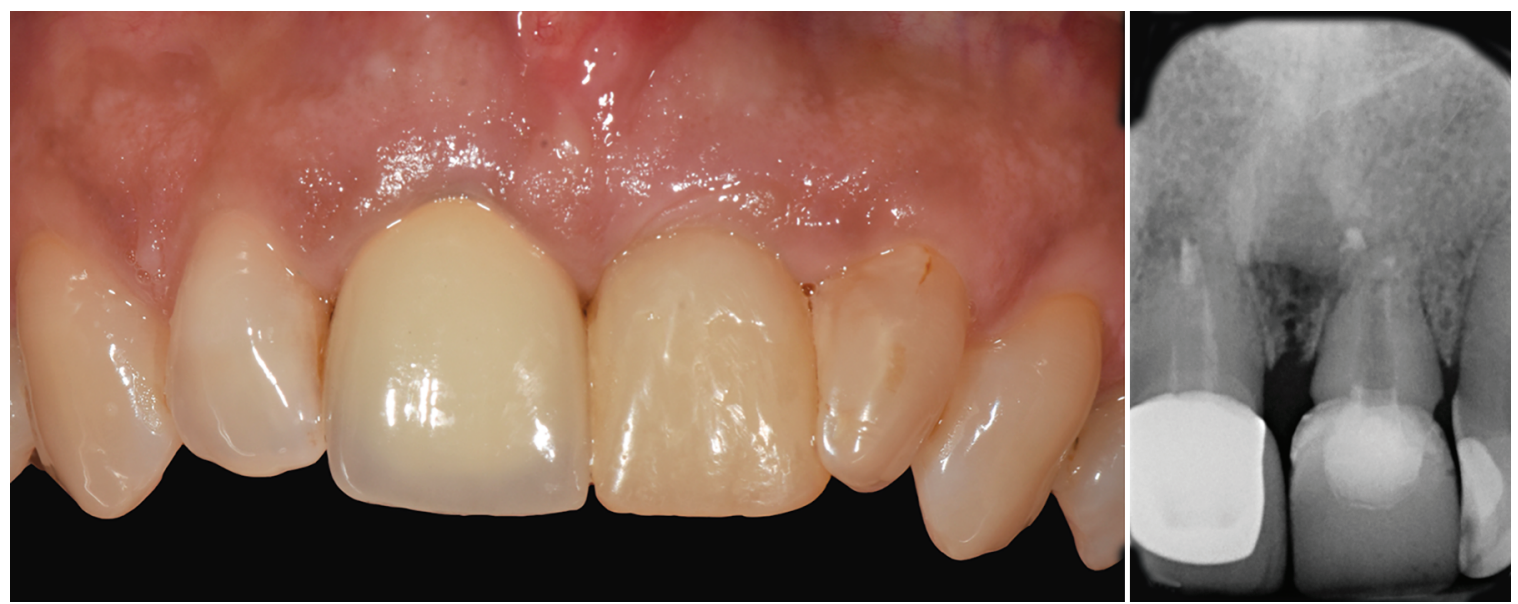

Fig. 1: Baseline, teeth 1.1 and 2.1 were scheduled for extraction

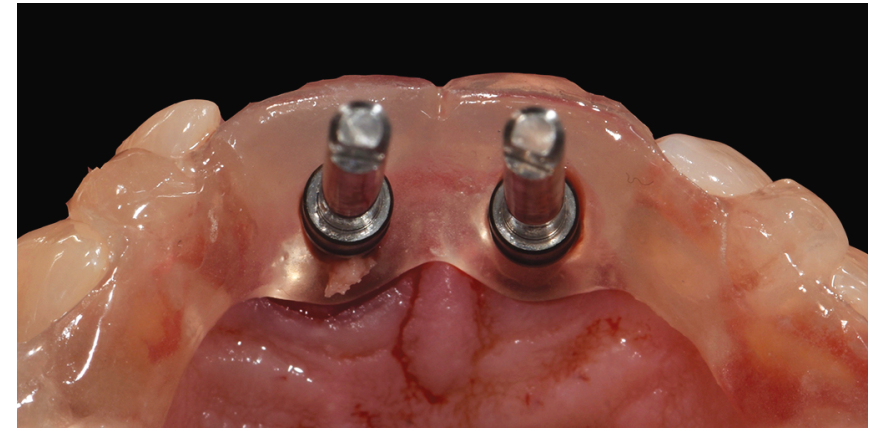

Fig. 2: Placement of two dental implants with the surgical stent

Ivoclar Vivadent ${ }^{\oplus}$ Naturno (BZ), Italy) at the lingual aspect of the teeth 1.4, 1.3, 1.2, 2.2, 2.3, and 2.4.

At the 12th week visit, the provisional was removed, and a second-stage flapless surgery was performed. A reverse-torque test of the two implants was completed at $15 \mathrm{~N} / \mathrm{cm}$ (confirming osteointegration). Periapical digital X-rays were taken, and the healing abutment (CLC SCIENTIFIC ${ }^{\circledast}$, Vicenza, Italy) was placed (Fig. 4).

At the time of the provisional screw-retained prosthesis delivery, the gingival margin of implant 2.1 was apically positioned. Moreover, a volume deficiency was present, and a partial loss of the interdental papilla between the two central incisors was observed (Fig. 5A).

At that moment, it was decided to start the soft tissue conditioning in the peri-implant area by modifying the critical and subcritical contour. Su et al. in 2010 defined two different areas within the transgingival zone based on the response of the periimplant gingival tissues to abutment/crown contour modifications: the critical and subcritical contour. The former is the $1-1.5 \mathrm{~mm}$ subgingival area, apical to the free gingival margin. The contour modification of this zone impacts the buccal-gingival margin level, zenith, and crown shape. The subcritical contour is located apical to the critical contour zone and provides the "running room" necessary to achieve a correct emergence of the restored teeth. In addition, its modification may influence interdental papilla growth. ${ }^{12}$

The first step in the soft tissue conditioning process was the determination of the desired gingival margin. Subsequently, the prosthesis was removed, and the facial critical contour was reduced using a handpiece burr, while the convexity of the subcritical contour was increased by adding flowable composite (Tetric Evo Flow $^{\circledast}$, Ivoclar Vivadent ${ }^{\oplus}$ Naturno (BZ), Italy) in a facial/apical direction instead (Figs 6A and B). Finally, the interproximal contact point was moved coronally and the interproximal convexity was a slight increase to squeeze the interdental papilla and obtain a slight increase in height. The restoration was polished using several rubber systems with different granulations.

The patient was evaluated after 2 weeks. At this time, an improvement in the soft tissue contour was observed with a 0.4-mm of coronal displacement of the gingival margin. Subsequent modifications were required. The critical convexity and the length of the clinical crown of the 2.1 were slightly reduced once. It is important to note that the modification should follow a precise timeline and an interval of 15 days is recommended to allow for healing and revascularization of the peri-implant mucosa. ${ }^{13}$

One month later, the soft tissue conditioning was completed: not only soft tissue thickening and coronally interproximal papilla migration can be appreciated but also a continuous firm gingival margin rather than the irregular flat at the baseline (Fig. 5B). At this point, the definitive screw-retained restoration was fabricated and delivered (Fig. 5C).

Finally, the patient was enrolled in a strict maintenance therapy program and a stable outcome was seen in the follow-up after 12 months (Fig. 5D).

\section{Discussion}

To achieve a natural appearance of the restoration, the use of a provisional restoration is recommended, and soft tissue conditioning of the soft tissue can be obtained with several techniques. ${ }^{12,14-16}$ In our case report, due to the low primary stability at the time of implant placement, the implants were left submerged and immediate esthetics were obtained with a Maryland bridge. The ovate pontic had a convex shape that applied slight pressure on the soft tissues preserving the scalloped outline of the mucosa and helping the maintenance of the interdental papilla. ${ }^{16}$ The literature reports that mucosal recession is the most frequent complication after IIP, ${ }^{4}$ and this occurs in the presented clinical case. Slight esthetic problems can be managed by progressively customizing the provisional prosthesis to obtain a natural transition between the restoration and the soft tissues. ${ }^{12,13}$ The described protocol applied two concepts: the simple reduction of the facial 
volume of the restoration leads to a thickening of the soft tissue ${ }^{17}$ and that the crowns' shape can modify the position of the mucosal margin and favors the growth of the interproximal papilla. ${ }^{12,13,18}$ Nevertheless, the design of the implant (platform switching) used helped to preserve peri-implant bone loss and interproximal bone peak hence leads to a better chance for the formation of the interimplant papilla ${ }^{19}$ and anatomic characteristics at the surgical site play a role in the result of this clinical case. The result achieved in this case demonstrates that slight soft-tissue deficiencies around the implant could be successfully managed by modifying the critical and subcritical areas.
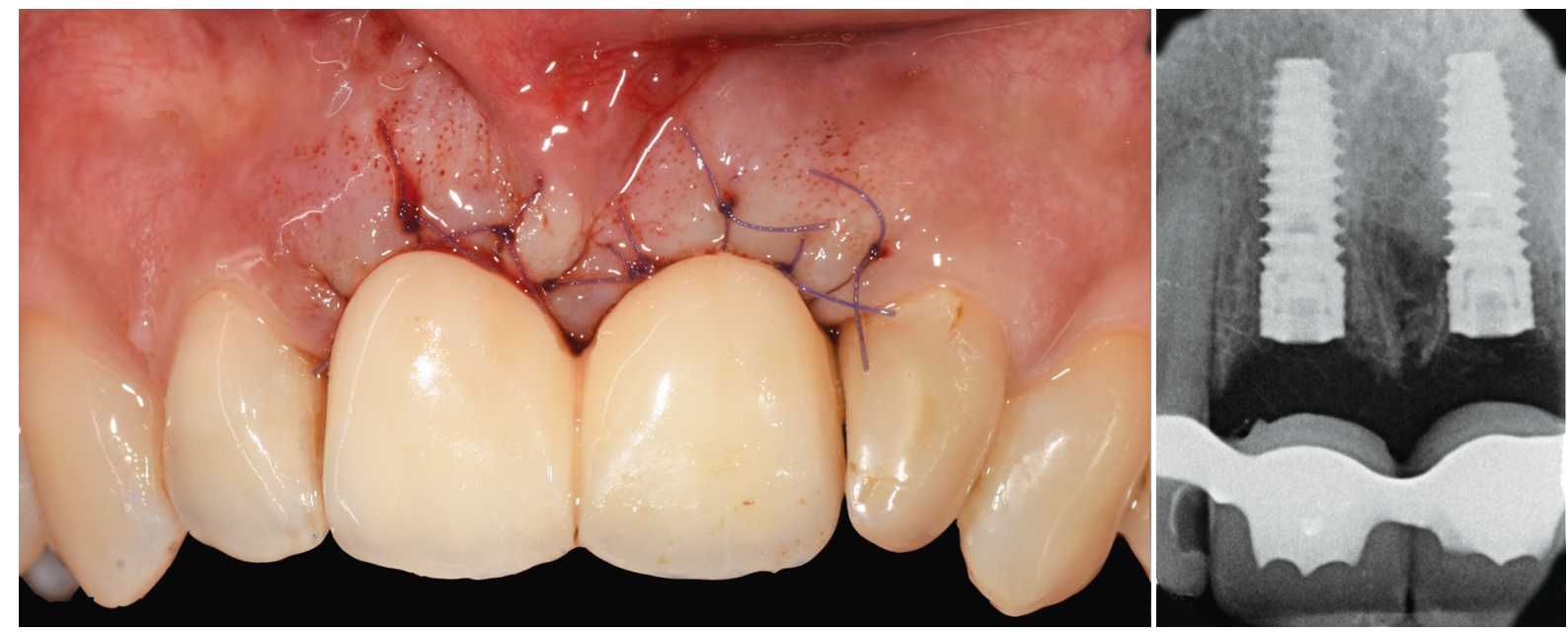

Fig. 3: Postoperative viewed after the Maryland bridge cementation and X-ray of the two implants after placement
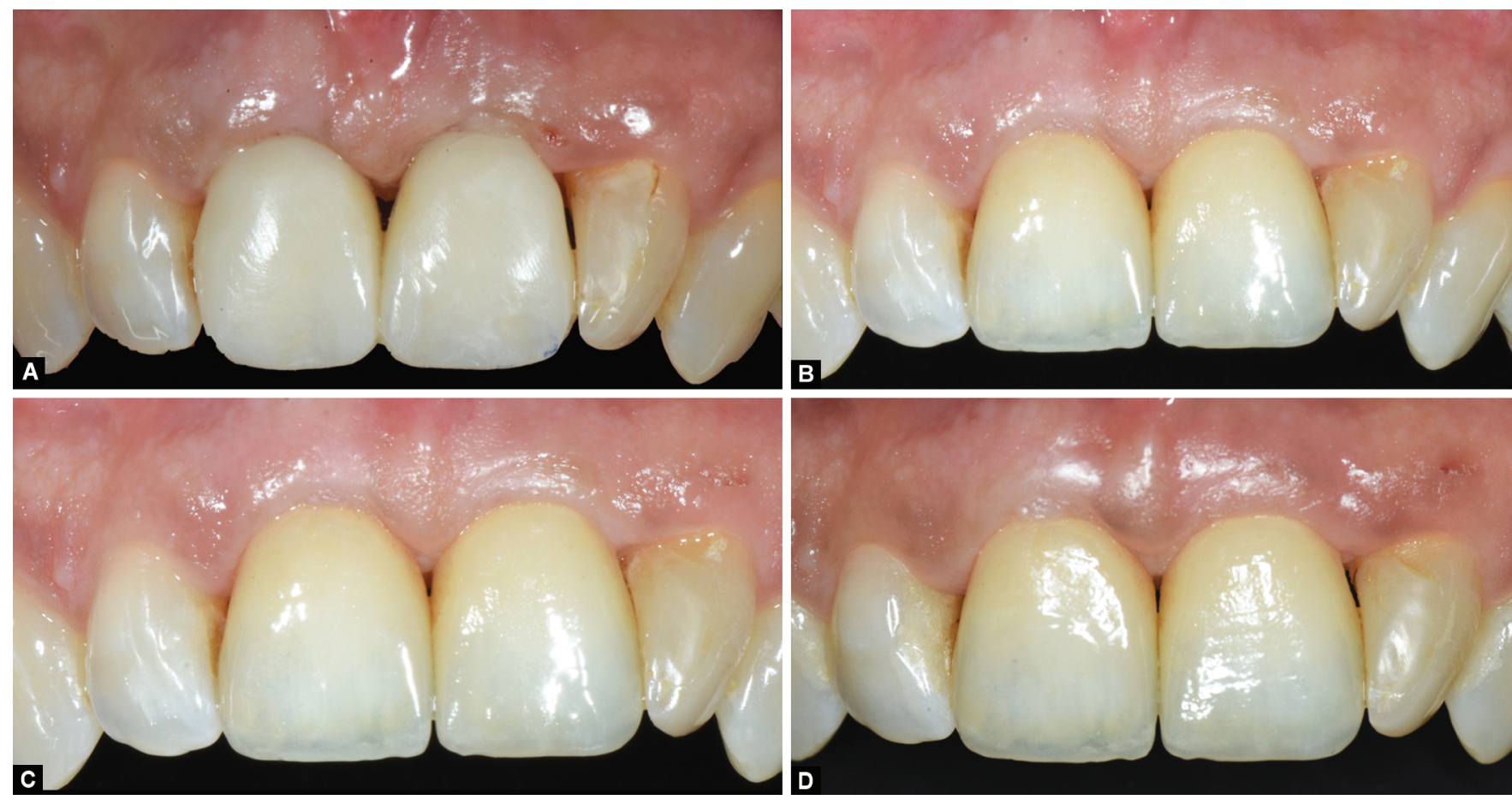

Figs 5A to D: (A) Immediately after screwed retained provisional delivered; (B) After 2 weeks from prosthesis modification; (C) At the time of the definitive prosthesis delivery; (D) 1-year follow-up, the esthetic outcome remains stable 


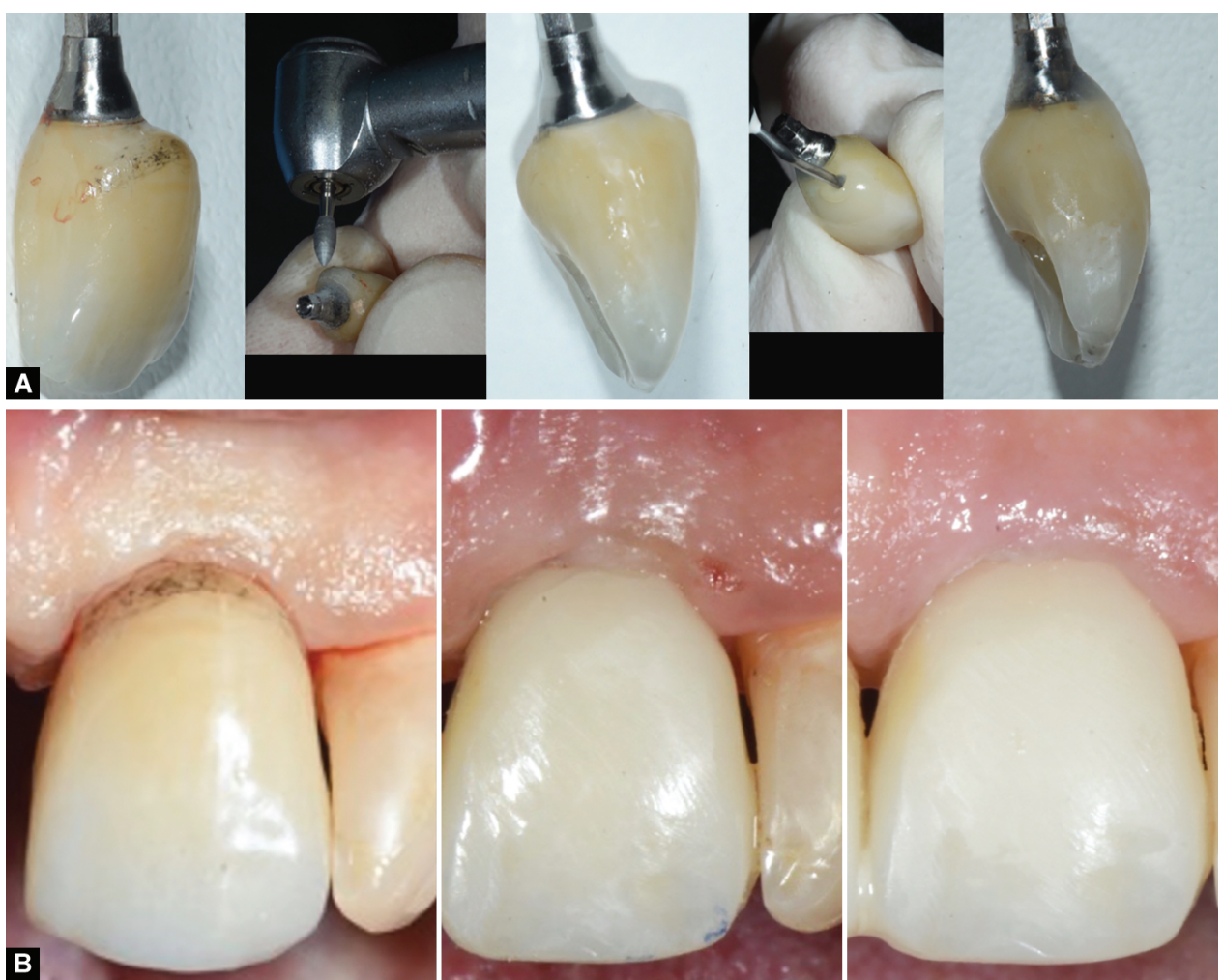

Figs 6A and B: (A) Step of prosthesis modification: Facial critical contour was reduced using a hand piece burr, while the convexity of the subcritical contour was increased by adding flowable composite; (B) Close-up view of the soft tissue conditioning at baseline, after prosthesis modification, and after 2 weeks

This case report describes a technique to improve the outcome of the peri-implant tissues by shaping the critical and subcritical contours of the implant emergence profile during the provisionalization phase. This technique shows optimal results in terms of esthetics and soft tissue stability, avoiding the need for a second surgical intervention.

\section{ACKNOWLedgment}

General information about the protocol, material selection, and hygiene was discussed extensively, and informed consent with clear indications as to risks and benefits was obtained from the patient.

\section{References}

1. Tonetti MS, Jung RE, Avila-Ortiz G, et al. Management of the extraction socket and timing of implant placement: consensus report and clinical recommendations of group 3 of the XV European workshop in periodontology. J Clin Periodontol 2019;46(Suppl 21):183-194. DOI: 10.1111/jcpe.13131.

2. Lang NP, Pun L, Lau KY, et al. A systematic review on survival and success rates of implants placed immediately into fresh extraction sockets after at least 1 year. Clin Oral Implants Res 2012;23(Suppl 5):39-66. DOI: 10.1111/j.1600-0501.2011.02372.x.

3. Tonetti MS, Cortellini P, Graziani F, et al. Immediate versus delayed implant placement after anterior single tooth extraction: the timing randomized controlled clinical trial. J Clin Periodontol 2017;44(2):215224. DOI: $10.1111 /$ jcpe.12666.

4. Chen ST, Buser D. Esthetic outcomes following immediate and early implant placement in the anterior maxilla-a systematic review. Int
J Oral Maxillofac Implants 2014;29(Suppl):186-215. DOI: 10.11607/ jomi.2014suppl.g3.3.

5. Araújo MG, Lindhe J. Dimensional ridge alterations following tooth extraction. An experimental study in the dog. J Clin Periodontol 2005;32(2):212-218. DOI: 10.1111/j.1600-051X.2005.00642.x.

6. Kan JY, Rungcharassaeng K, Sclar A, et al. Effects of the facial osseous defect morphology on gingival dynamics after immediate tooth replacement and guided bone regeneration: 1-year results. [published correction appears in J Oral Maxillofac Surg. 2008 Oct;66(10):2195-6] J Oral Maxillofac Surg 2007;65(7 Suppl 1):13-19. DOI: 10.1016/j.joms.2007.04.006.

7. Raes F, Cosyn J, Crommelinck E, et al. Immediate and conventional single implant treatment in the anterior maxilla: 1-year results of a case series on hard and soft tissue response and aesthetics. J Clin Periodontol 2011;38(4):385-394. DOI: 10.1111/j.1600051X.2010.01687.x

8. Cosyn J, Eghbali A, Hermans A, et al. A 5-year prospective study on single immediate implants in the aesthetic zone. J Clin Periodontol 2016;43(8):702-709. DOI: 10.1111/jcpe.12571.

9. Chen ST, Darby IB, Reynolds EC. A prospective clinical study of nonsubmerged immediate implants: clinical outcomes and esthetic results. Clin Oral Implants Res 2007;18(5):552-562. DOI: 10.1111/j.16000501.2007.01388.x.

10. Canullo L, lurlaro G, lannello G. Double-blind randomized controlled trial study on post-extraction immediately restored implants using the switching platform concept: soft tissue response. Preliminary report. Clin Oral Implants Res 2009;20(4):414-420. DOI: 10.1111/j.16000501.2008.01660.x.

11. De Rouck T, Collys K, Wyn I, et al. Instant provisionalization of immediate single-tooth implants is essential to optimize esthetic treatment outcome. Clin Oral Implants Res 2009;20(6):566-570. DOI: 10.1111/j.1600-0501.2008.01674.x. 
12. Su H, Gonzalez-Martin $\mathrm{O}$, Weisgold $\mathrm{A}$, et al. Considerations of implant abutment and crown contour: critical contour and subcritical contour. Int J Periodontics Restorative Dent 2010;30(4):335-343.

13. González-Martín O, Lee E, Weisgold A, et al. Contour management of implant restorations for optimal emergence profiles: guidelines for immediate and delayed provisional restorations. Int J Periodontics Restorative Dent 2020;40(1):61-70. DOI: 10.11607/prd.4422.

14. Wittneben JG, Buser D, Belser UC, et al. Peri-implant soft tissue conditioning with provisional restorations in the esthetic zone: the dynamic compression technique. Int J Periodontics Restorative Dent 2013;33(4):447-455. DOI: 10.11607/prd.1268.

15. Yao JW, Wang HL. Assessment of peri-implant soft tissue adaptive pressure and time after provisional restorations. Int J Periodontics Restorative Dent 2019;39(6):809-815. DOI: 10.11607/prd.4063.
16. Ozdemir E, Lin WS, Erkut S. Management of interproximal soft tissue with a resin-bonded prosthesis after immediate implant placement: a clinical report. J Prosthet Dent 2012;107(1):7-10. DOI: 10.1016/S00223913(12)60008-0.

17. Zucchelli G, Mazzotti C, Mounssif I, et al. A novel surgical-prosthetic approach for soft tissue dehiscence coverage around single implant. Clin Oral Implants Res 2013;24(9):957-962. DOI: 10.1111/clr. 12003.

18. Clavijo V, Blasi A. Decision-making process for restoring single implants. Quintessence Dent Technol 2017;40:66-88.

19. Rodríguez-Ciurana X, Vela-Nebot X, Segalà-Torres M, et al. The effect of interimplant distance on the height of the interimplant bone crest when using platform-switched implants. Int J Periodontics Restorative Dent 2009;29(2):141-151. 